TITLE:

\title{
Alteration of epigenetic program to recover memory and alleviate neurodegeneration: prospects of multi-target molecules
}

\section{AUTHOR(S):}

Pandian, Ganesh N.; Taylor, Rhys D.; Junetha, Syed; Saha, Abhijit; Anandhakumar, Chandran; Vaijayanthi, Thangavel; Sugiyama, Hiroshi

\section{CITATION:}

Pandian, Ganesh N....[et al]. Alteration of epigenetic program to recover memory and alleviate neurodegeneration: prospects of multi-target molecules. Biomaterials Science 2014, 2(8): 1043-1056

\section{ISSUE DATE:}

2014-06-09

URL:

http://hdl.handle.net/2433/198838

\section{RIGHT:}

This journal is (C) The Royal Society of Chemistry 2014.; This is not the published version. Please cite only the published version.; この論文は 出版社版でありません。引用の際には出版社版をご確認ご利用くださ い。 


\section{Alteration of epigenetic program to recover memory and alleviate neurodegeneration: Prospects of multi-target molecules}

Ganesh N. Pandian ${ }^{\mathrm{a}}$, Rhys D. Taylor ${ }^{\mathrm{b}}$, Syed Junetha ${ }^{\mathrm{b}}$, Abhijit Saha ${ }^{\mathrm{b}}$, Chandran Anandhakumar ${ }^{\mathrm{b}}$, Thangavel Vaijayanthi ${ }^{\mathrm{b}}$ and Hiroshi Sugiyama ${ }^{\mathrm{a}, \mathrm{b}^{*}}$

anstitute for Integrated Cell-Material Sciences (iCeMS), Kyoto University, Sakyo, Kyoto 606-8502, Japan.

${ }^{\mathrm{b}}$ Department of Chemistry, Graduate School of Science, Kyoto University, Sakyo, Kyoto 606-8501, Japan.

*Corresponding author: Professor Hiroshi Sugiyama, Department of Chemistry, Graduate School of Science, Kyoto University, Sakyo, Kyoto 606-8501, Japan. Tel: +81-75-753-4002 and Fax: +81-75-753-3670, Email: hs@kuchem.kyoto-u.ac.jp 


\section{Abstract}

Epigenetic chromatin remodeling and signalling pathways play an integral role in the transcription dependent neurodegeneration and long-term potentiation (LTP), a cellular model associated with learning and memory. Pathological epigenetic modifications associating with neurological disorders are inherently flexible and can be reversed through pharmacological interventions. Small molecules are the favored drugs for clinicians, and in neurological disorders associated with complex cellular mechanisms, epigenetic and/or signalling pathway enzyme inhibiting small molecules have shown clinical prospects. Recently, small molecules with two or more functional activities such as sequence-specific recognition and signalling pathway and/or enzyme modulation have shown the capability as efficient transcriptional activators. Here, we give a balanced overview of the key factors associated with memory recovery and neurodegeneration, available chemical tools for modulation and the demand to develop next-generation small molecules with multi-functional activities to treat such intricate, multi-gene associated neurological disorders. 


\section{Introduction}

More small molecules enter the clinic as new drugs than any other drugs such as vaccines, peptides, and siRNA. ${ }^{1}$ Modern biological and analytical techniques assist us to attain huge biological information, which can be harnessed to devise novel therapeutic strategies for some complex disorders such as neurological diseases. ${ }^{2}$ Information is not only a powerful but also a critical resource that needs meticulous management and regulation. In living systems, DNA serves as the informational molecule that can store and retrieve the genetic instructions conferring the development and characteristics of all known living organisms. ${ }^{3,4}$ The term 'memory' could be defined as the process by which the information gets encrypted, accumulated, and recovered. From a functional point of view, memory is relevant to DNA because both encode, store and retrieve information and function as rewritable data storage in living cells. ${ }^{5}$ Depending on the mode, duration and capacity of storage, memory can be broadly classified into three types: 1) sensory memory, 2) short-term memory and 3) long-term memory. ${ }^{6}$ Long-term memory and its storage at the cellular level are associated with gene transcription/translation. Also, studies using protein synthesis inhibitors have further verified this phenomenon as only the enduring memories were blocked. ${ }^{7}$ Cognitive processes like learning and memory are often associated with Long-term potentiation (LTP), a process that modulates the changes in neural synapses by enhancing the signal strength between neurons. ${ }^{8}$ Based on the distinctive molecular mechanisms, LTP gets categorized into two phases. The transcription independent early phase that lasts for about 3 hours while the transcription/translation- dependent late phase can last up to even several weeks under in vivo conditions. ${ }^{9}$ Interestingly, this transcription dependency aspect of LTP is analogous with memory. N-methyl-d-aspartate (NMDA) and its action on its 
receptors steer the influx of calcium and initiate phosphorylation of ERK (extracellular signal-regulated kinase), which in turn induces and maintains LTP.9 Studies with various histone deacetylase (HDAC) inhibitors and neural development have shown that in most cases, enrichment of the total acetylation rates in the brain can lead to an increased rate of transcription, which in turn can aid the memory process. ${ }^{10,11}$ CREB, a cAMP response element and transcriptional activator, bind with the transcriptional co-activator CBP (CREB-binding protein) to form a CREB:CBP complex for the activation of the target hippocampus-dependent, long-term memory associated genes. ${ }^{12}$ Haettig et al. implied the essential role of CBP through studies in mouse behavioural models where the HDAC inhibition was shown to modulate longterm memory for object recognition. ${ }^{13}$ Their studies with systemic delivery of a HDAC inhibitor also suggested that different chromatin-modifying enzymes control distinctive memory-related genes in different brain regions. Although neurons are non-proliferating and terminally differentiated cells, the cellular proliferation- and differentiation-associated proteins, and protein kinase cascades were shown to be vital for long-term memory formation. ${ }^{9,14-17}$ Recent developments in functional genomics reveal the essential role of noncoding RNAs (ncRNAs) in the regulation of chromatin remodelling, which control the transcriptional programs conferring to LTP. ${ }^{18}$ The ncRNAs are generally accepted to contribute towards the intricacy and function of the mammalian brain. ${ }^{19}$ The ncRNAs play a vital role in LTP and are found more predominantly in the nervous system. ${ }^{20}$ For example, Scott et al.. demonstrated through expression and functional deficit studies that miR-132 could co-ordinate the intricate transcriptional machinery associated with the synaptic mechanisms controlling the memory formation. ${ }^{21}$ Thus, despite extensive available literature, it is hard to generalize cellular and molecular mechanisms conferring the inception, 
consolidation, and retention of memory. The existing information regarding memoryassociated mechanisms is acquired through studies on neurological disorders. ${ }^{22}$ Several studies with HDAC-inhibiting small molecules have substantiated the essential role of epigenetics and transcriptional activation in memory formation and neurological disorders. ${ }^{23}$ Because alterations in epigenetic program are merely a small part of a huge complicated interaction of signalling pathways controlling the mechanism of LTP expression, a comprehensive overview of the molecular mechanisms underlying LTP is beyond the scope of this review.

In this review, we give a brief overview of the epigenetic aspect of transcription dependent LTP, an underlying cellular phenomenon associated with several neurological disorders. Also, by summarizing the potential of individual available bioactive small molecules, we suggest the importance of developing next generation small molecules with multiple activities such as i) HDAC inhibition, ii) signaling factor inhibition, iii) sequence-specific recognition, and iv) other such biologically significant properties. Development of such doubly active or multi-target small molecules can have a significant impact in elucidating the molecular mechanisms such as LTP, which in turn may lead to effective treatment for complex neurological disorders.

\section{Long-term potentiation and memory}

\subsection{Long-term potentiation - A brief overview}

Neurons are the fundamental building blocks of the nervous system, which manages the intricate organization of how humans sense, perceive, and act. Santiago Ramón y Cajal, an eminent neuroanatomist ${ }^{24}$ first proposed that memories could be formed by improving the efficacy of neural communication through strengthening of the 
connections between existing neurons. In 1949, Donald Hebb reiterated this view and proposed a theory that cells develop fresh connections or undergo metabolic changes to enhance the communication capacity. ${ }^{25}$ In 1966, Terje Lømo discovered the process of long-term potentiation through a series of neurophysiological experiments on anesthetized rabbits and explored the relationship between short-term memory and the role of the hippocampus, a region long known to be essential for learning and memory. ${ }^{26}$ Subsequent reports characterized this phenomenon, and in 1975, Douglas and Goddard termed this phenomenon "long-term potentiation or LTP" ${ }^{27}$ LTP occurs in other neural structures like the cerebral cortex, cerebellum and amygdala in the mammalian brain. ${ }^{28}$ Since different areas of the brain exhibit different forms of LTP, many factors such as age and anatomical location influence the specific type of LTP. ${ }^{29}$ For studies on mammalian LTP, the CA1 hippocampus gets preference owing to its predictable organization and readily inducible LTP. ${ }^{28}$ LTP gains prominence over other kinds of synaptic plasticity owing to its ability to persist and last from several minutes to months. ${ }^{30}$ Activation of NMDA receptors in hippocampal neurons trigger early phase LTP through the activation of calcium-dependent kinases and involves an increase in the synaptic AMPA ( $\alpha$-amino-3-hydroxy-5-methyl-4isoxazolepropionic acid) receptor function. ${ }^{31}$ While early phase LTP is independent of protein synthesis, late phase LTP requires the persistent activity of atypical protein kinase $\mathrm{C}$ isoform $(\mathrm{PKM} \zeta)$ for active synaptic transmission in the central nervous system and to maintain an increased amount of AMPA receptors at potentiated synapses to consolidate memory. ${ }^{32}$ Transcription factors like Zif 268 are suggested to trigger the signalling of $\mathrm{PKM} \zeta$ gene activation. ${ }^{33}$ Whitlock et al. demonstrated through inhibitory avoidance learning experiments in rats that learning induces similar changes in hippocampal glutamate receptors like those observed in high 
frequency stimulation-inducted LTP. ${ }^{34}$

\subsection{LTP in neurological disorders}

Impaired long-term potentiation plays an important role in the pathology of many neurodegenerative disorders that can be either progressive or immediate. Alzheimer's disease $(A D)$ is an extensively studied progressive neurodegenerative disease characterized by the abnormal processing of amyloid precursor protein (APP), hyperphosphorylation of tau protein, apoptotic-like cell death, cognitive decline and defective memory. ${ }^{35}$ Synaptic loss and dysfunction are the two main features associated with the cognitive decline in $\mathrm{AD}$, which are attributed to soluble amyloid beta $(\mathrm{A} \beta)$ in the brain of $\mathrm{AD}$ patients. $\mathrm{A} \beta$ oligomers inhibit LTP and facilitate long term depression, a slow, weak electrical stimulation of CA1 neurons that reduce the number of AMPA receptors at the synapse. ${ }^{36}$ In addition, there are reports that AD impairs LTP by the accumulation of the enzyme protein kinase $\mathrm{M}$ zeta $(\mathrm{PKM} \zeta)$ in neurofibrillary tangles suggesting a link between PKM $\zeta$-mediated synaptic plasticity and memory impairment in $\mathrm{AD} \cdot{ }^{37}$ On account of the fact that $\mathrm{AD}$ is still incurable, a deeper understanding of the complex mechanisms such as epigenetic dysfunction associated with this neurodegenerative disease is of increasing importance. ${ }^{38}$ Graff et al. showed that the hippocampus region in human $\mathrm{AD}$ brain has elevated levels of HDAC2, the enzyme known to modulate gene transcription associated with learning. ${ }^{39}$ Therefore, developing strategies to alter the epigenetic program could be useful in treating AD.

Huntington's disease (HD) is an autosomal dominant neurodegenerative disorder that is characterized with the progressive motor dysfunction, dementia, and psychiatric disturbance. Genetic and phenotypic studies of animal models of HD 
reveal certain LTP alterations. Crupi et al. discussed the possibility of the damage of LTP-like plasticity due to the alterations of the neuronal circuits in HD patients. ${ }^{40}$ Dallerac et al. showed that the D1 dopamine receptor activation rescued the impaired LTP in the mouse model of HD disease. ${ }^{41}$ Costa et al. showed that L-DOPA restores the hippocampal synaptic potentiation through D1/D5 receptors and improves the cognitive deficit in experimental models of Parkinson's disease. ${ }^{42}$ Transcriptional abnormalities leading to neuronal damage in HD are often associated with epigenetic alterations. The epigenetic enzymes known to control gene transcription such as DNMT and HDAC have been envisaged as potential therapeutic targets in HD treatment. ${ }^{43}$ Other major disorders include amnesia, where memory and learning are affected among other cognitive functions, and agnosia, which is characterized by the inability to recognize certain objects, persons, or sounds. Because the loss of cognition is the common manifestation of these neurological disorders, strategies to regulate LTP could aid us to gain insights into general cellular mechanisms and facilitate strategies to treat cognitive impairment.

\subsection{Transcription factor-mediated reprogramming for neurogenesis and cell replacement therapy}

Neurogenesis, a dynamic cellular process that validates the precise functioning of learning and memory processes could be achieved through the activation of cell fate specific transcription factors. Watanabe et al. showed the conversion of $\mathrm{C} 2 \mathrm{C} 12$ myoblasts into neurons by overexpressing a recombinant form of REST (RESTVP16), which contains the transcriptional activation domain of the herpes simplex virus protein VP16. ${ }^{44}$ Vierbuchen et al. reprogrammed mouse embryonic and postnatal fibroblast cells into neurons by ectopic expression of three transcription 
factors Asc11, Brn2, and Myt11. ${ }^{45}$ Neural stem cells (NSCs) that are capable of selfrenewal or differentiation can generate new neurons and have a debatable role in alleviating the memory loss after getting transplanted in transgenic mouse AD models. ${ }^{46}$ An essential role of BDNF (brain derived neurotrophic factor) for the functional effect of transplanted NSCs was demonstrated in a study that clearly showed that only the rats that received stem cells and BDNF and not the control animals, preserved learning and memory. ${ }^{47}$ Some of the LTP associated genes/factors, which are the potential targets of cellular reprogramming and their characterized role in human and animal models are listed in Table $1 .{ }^{48-56}$

\section{Table 1.}

Along with some of these key signal transduction factors, epigenetic modifications also got associated with cognitive recognition. ${ }^{57}$

\section{Epigenetic enzyme inhibitors for transcriptional}

\section{activation}

\subsection{HDAC and DNMT inhibiting small molecules for memory recovery}

There are two major epigenetic mechanisms involved in learning and memory: 1) modification at cytosines in $\mathrm{CpG}$ dinucleotide sequences by methylation; and 2) chromatin remodelling. Studies with animal models using different learning and memory methods, ${ }^{58}$ and with a post-mortem of the human brain ${ }^{59}$ to endorse this phenomenon. The methylation of both DNA and the histone proteins has been implicated in LTP and memory formation ${ }^{60}$. DNA methylation inducing DNA methyl transferases (DNMTs) such as DNMT1, DNMT3a, and DNMT3b are differentially expressed within the adult brain and suggest its critical role in cognition. ${ }^{61}$ Recent studies have shown that by blocking DNMT activity with inhibitors 5-AZA-dC and 
zebularine, contextual fear-conditioned memory formation could be disrupted. ${ }^{62}$ DNMT inhibition also resulted in increased expression level of the memorystimulating gene Reelin through promoter demethylation whereas a decreased expression level of memory-suppressing genes like PPI1 was also observed. ${ }^{63}$ Taken together, it is evident that epigenetic regulation of memory promoting genes form a complex pattern as these processes cross-talk, interact with, and influence each other.

HDAC enzymes govern the gene transcription by conserving them in heterochromatin architecture and regulating the chromatin-remodelling event. Histone deacetylase inhibitors (HDACi) like trichostatin A (TSA) and vorinostat [suberoylanilide hydroxamic acid (SAHA)] are capable of inhibiting HDACs with varying efficiency (at nanomolar to millimolar concentrations) and causes hyperacetylation of histones, which in-turn triggers transcriptional activation of certain genes through relaxation of the DNA conformation. ${ }^{64}$ However, HDAC inhibition always does not always restore the transcription of the gene under investigation. For instance, Lopez-Atalaya et al. showed through chromatin immune precipitation sequencing and gene expression profiling studies that TSA had only a moderate effect on hippocampal gene expression. ${ }^{65}$ Proteins other than histones can be deacetylated by HDACs owing to the involvement of HDACs in many complex cellular processes. ${ }^{66,67}$ Prolonged treatment of adult rat neural progenitors with valproic acid (VPA), a known HDAC inhibitor, resulted in the reduced proliferation of adult neural progenitors, but observed an increase in neuronal differentiation. ${ }^{68}$ Further examinations showed an increase in the Neurodl mRNA level, a transcription factor required for the neuronal differentiation after VPA treatment. ${ }^{69} \mathrm{Yu}$ et al. showed that VPA intensely repressed the proliferation of progenitor cells and increased the neuronal differentiation by inducing the expression of proneuronal 
transcription factors such as Ngn1, Math1, and p15 that contribute to neuronal differentiation. $^{70}$ VPA has also been shown to effectively block the aberrant neurogenesis and prevent the hippocampal seizures induced cognitive impairment. ${ }^{71}$ Kim et al. showed that neurogenesis is stimulated in the brain of ischemic rat models with $\mathrm{NaB}$ treatment. ${ }^{72}$ Overall, HDACi positively regulate differentiation of newborn neurons and has a potential in treating cognitive impairment. ${ }^{73}$ Also, a number of inhibitor-based experiments verified that HDACs can negatively regulate long-term memory formation. ${ }^{74,75}$ Recent studies on individual HDACs and their effects on LTP have revealed that $\mathrm{HDAC} 2$, and not $\mathrm{HDAC} 1$, is a key HDAC for regulating memory formation. ${ }^{76}$ HDAC3 is also known to negatively regulate memory formation. ${ }^{77}$ Table 2 details the enzymes that are associated with a specific neurological disorder. ${ }^{78-82}$

Table 2.

The process of aging results in reduced acetylation of histones $\mathrm{H} 3$ and $\mathrm{H} 4$ in the promoter regions of the BDNF gene to suppress its expression and significantly contribute to the deficits in hippocampal synaptic structure and function. ${ }^{83}$ These changes can be repaired by HDAC inhibition or selective activation of trkB receptors. Taken together, a chromatin-modifying enzyme like HDAC is a potential therapeutic target that can generate a form of long-term memory, which persists beyond a point at which normal memory fails (Fig. 1).

(Fig. 1)

\subsection{Therapeutic potential of HDACi in memory recovery}

Pharmacological intervention of histone acetylation using HDACi has been useful to treat memory impairment in neurodegenerative disorders and to enhance cognition. ${ }^{84}$ However, the therapeutic use of HDACi needs careful validation as studies in mice and some observations in patients have shown that memory-related processes could 
be impaired with chronic HDAC inhibition. ${ }^{85-87}$ By forming a complex with HDACs, methyl-CpG binding protein 2 (Mecp2) is believed to act as a transcriptional modulator in the basolateral amygdala (BLA) and is required for normal anxiety behaviour as well as certain types of learning and memory. ${ }^{88}$ Adachi et al. suggested the key role of Mecp2 as a transcriptional repressor in Rett Syndrome, an X-linked neurodevelopmental disorder. ${ }^{89}$ By infusing SAHA, they explored the effect of histone $\mathrm{H} 3$ acetylation on the anxiety phenotype of BLA-specific MECP2 knockdown mice. However, the SAHA infused mice demonstrated increased anxiety like behaviour and impaired cue-dependent fear learning. This result is in contrast with that observed with a single drug dose, and the saturation of changes in neuronal plasticity due to the chronically elevated histone acetylation was hinted to be the reason. ${ }^{89}$ Since anxiety is a complex behaviour that is mediated by a combination of genes, SAHA may have targeted other genes not regulated by MeCP2. Hence, these molecules should be designed with the ability to recognize specific region(s) in the brain as genes and systems required for LTP maintenance in one brain-region may not be required in the other. These findings demonstrate a potential shortcoming of employing the HDACis such as SAHA to recover memory as they may produce undesirable psychiatric behavioural side effects and warrants the need for customizing them to induce specific genes.

\subsection{Therapeutic potential of HDACi in neurological disorders}

Memory loss and cognitive dysfunction are not typical characteristics of Friedrich's ataxia (FRDA), a neurodegenerative disease caused by transcriptional repression of the FXN gene encoding the essential mitochondrial protein, Frataxin. ${ }^{90}$ However, chemical approaches developed to treat this transcription dependent disorder could be 
mimicked for memory related disorders. For example, HDACis like SAHA, TSA, and sodium butyrate had no notable effect on FXN transcription in non-FRDA cells. However, the commercially available HDACi BML-210 and its derivative efficiently induced the silenced FXN gene in lymphoid cell lines derived from FRDA patients and increased the level of Frataxin in cells. ${ }^{91}$ In neurodegenerative HD, aberrant transcription caused by the mutant huntingtin involves functionally defective transcription factors and coactivators like CBP, which impair the CBP/CREB mediated gene expression and histone deacetylation. ${ }^{92,93}$ Steffan et al. suggested the therapeutic potential of a HDACi in $\mathrm{HD}$, as the use of HDACi inhibited the polygultamine-dependent neuronal degeneration and reduced lethality in a Drosophila model. ${ }^{94}$ Subsequently, Ferrante et al. showed that the HDACi sodium butyrate triggered specificity protein-1 acetylation, and ameliorated the neurodegenerative phenotype in R6/2 transgenic mouse model of HD. ${ }^{80}$ Administration of the HDACi phenylbutyrate at tolerable doses caused significant neuroprotective effects in the N171-82Q transgenic mouse model of HD. ${ }^{95}$ Preclinical trial experiments carried out in R6/2 HD mouse model showed that the HDACi SAHA ameliorated motor deficits by crossing the blood-brain barrier and increasing the histone acetylation in the brain. $^{96}$

Genome-wide gene analysis through microarray studies showed that the chronic oral administration of HDACi $4 \mathrm{~b}$, an analog of BML-210 reversed histone $\mathrm{H} 3$ hypoacetylation and ameliorated the disease phenotype and transcriptional abnormalities in HD transgenic mice. ${ }^{97}$ Conversely, Beconi et al. demonstrated the shortcomings in the potential employment of pimelic diphenylamide HDACi to treat neurological disorders. ${ }^{98}$ Evaluation of HDAC isoform selectivity, cellular activity, in vitro and in vivo ADME (absorption, distribution, metabolism and excretion) 
properties of $4 \mathrm{~b}$ have revealed that even when in vitro selectivity and binding mode were in agreement with previous reports, ${ }^{98}$ their physicochemical stability and metabolic characteristics casted serious doubts that CNS HDAC3 inhibition is a therapeutic target for HD. ${ }^{97}$ Hence, $4 \mathrm{~b}$ was unsuitable as a molecular tool to examine class I HDAC inhibition in vivo and the need for proper ADME assessment of compounds before the in vivo target validation and therapeutic application was proposed. Specificity and off-target effects are the key issues that hamper the employment of small molecules in biological studies. Many studies tend to focus on target genes but ignore changes in the expression of other genes. Because the small molecules used (e.g. TSA, SAHA, VPA) in the experiments could also hit other targets not related to chromatin-remodeling or epigenetic regulation. This is often the case when unreasonably high concentrations of drugs were used. In this regard, there has been a rising demand for programmed small molecules targeting specific gene(s).

\subsection{Programmable DNA binding small molecules in neurological disorders}

DNA stores heritable information over a long period of time using only four nucleobases. Hence, small molecules interacting with these nucleobases can significantly alter the mutations that confer a specific neurological disorder. $\mathrm{N}$ methylpyrrole- $N$-methylimidazole polyamides (PIPs) are cell-permeable small molecules capable of binding to the minor groove of DNA with an affinity that is comparable to that of transcription factors. ${ }^{99}$ PIPs bind to DNA following a binding rule, where an antiparallel pairing of $\mathrm{I}$ opposite $\mathrm{P}(\mathrm{I} / \mathrm{P})$ recognizes a $\mathrm{G}-\mathrm{C}$ base pair, while a $\mathrm{P} / \mathrm{P}$ pair recognizes $\mathrm{A}-\mathrm{T}$ or $\mathrm{T}-\mathrm{A}$ base pairs. Synthetic PIPs possessing an alkylating moiety have been successfully employed for selective gene silencing and to target cancer associated mutations. ${ }^{100,101}$ The interference of PIPs with transcription 
factors also has a positive induction effect, which suggests that PIPs can inhibit both basal and activated transcription. DNA-binding sequence-specific PIPs can potentially be used to reverse the effects and alter the FXN gene by targeting GAA TTC repeats. ${ }^{102}$ For a practical demonstration, Burnett et al. synthesized a PIP (P1) to target the 9-bp sequence, as in the GAA TTC repeat DNA sequence. These polyamides bound to the coding region of the gene without affecting transcription in mammalian cells. When polyamide P1-treated cell lines were taken from an FRDA patient who had a very low level $(6 \%-13 \%)$ of Frataxin protein and the results were compared with an unaffected sibling, it was found that the polyamide P1 increased the FXN transcription by about $2-3$-fold. Similar treatment with a mismatch polyamide showed a modest result. A recent study by Dervan and colleagues has shown that these polyamides do not fit into single-stranded RNA or duplex regions of RNA to suggest a lack of effect on the translation of Frataxin mRNA. ${ }^{103}$

\section{Small Molecules with Dual Characteristics: Progress and}

\section{Prospects}

\subsection{Sequence-specific epigenetic activators}

Recently, some novel strategies have emerged to achieve small molecules with versatile properties. One such novel small molecule termed SAHA-PIP encompasses both selective DNA-binding hairpin pyrrole-imidazole polyamides (PIPs) and the potent HDAC inhibitor, SAHA (Fig. 2A). The biological activity of SAHA-PIP was first demonstrated by synthesizing SAHA-PIPs that could sequence-specifically acetylate the promoter region of the tumour suppressor gene p16 in HeLa cells. ${ }^{104}$ When the effects of a library of distinct SAHA-PIPs were evaluated on the epigeneticdependent and complicated pluripotency gene network in mouse embryonic 
fibroblasts (MEFs), certain SAHA-PIPs differentially induced pluripotency genes through the initiation of epigenetic marks that confer transcription accommodating chromatin including histone H3 Lys9 and Lys14 acetylation. ${ }^{105,106}$ (Fig. 2B). An advanced version of SAHA-PIP termed, ' $\delta$ ' but not SAHA, rapidly induced multiple pluripotency genes. ${ }^{107}$ Interestingly, $\delta$-OMe, the non-functional SAHA-PIP did not activate any pluripotency genes to validate SAHA as the functional moiety in $\delta$. Because SAHA-PIP encompasses both HDAC inhibitory activity and sequencespecific binding ability, interpretation of a definite mechanism is challenging. About $33 \%$ of the $\delta$-induced genes belonged to the core pluripotency gene network that comprises of 345 inter-twined genes. Hence, it is reasonable to assume that the PIP in $\delta$ directs SAHA to the typically conserved core pluripotency gene network for sitespecific epigenetic modifications (Fig. 2B). Analysis of the number of matching sites in the Nanog gene further substantiates this notion. ${ }^{105}$ However, more studies are warranted to have a thorough understanding of the SAHA-PIP mediated epigenetic activation of certain genes. Recently, a SAHA-PIP termed ' $\mathrm{K}$ ' was shown to be the first-ever small molecule to enforce transcriptional activation of meiosis-regulating germ cell genes in a human somatic cell (Fig. 2C). It is important to note here that the meiotic process is specific to germ cells and could not occur in a somatic cell. ${ }^{108}$

(Fig. 2)

As shown before, both HDACi and PIPs were individually shown to be successful in treating neurodegenerative disorders but with certain disadvantages. Hence, conjugating them both to generate other HDACi-PIP could lead to sitespecific activation of genes associated with memory formation and neurodegeneration. Recently, a SAHA-PIP called ' $M$ ' was shown to distinctively activate a set of neurotransmitter genes including $N R X N$ and GPRC5B (Fig. 2D). ${ }^{109}$ SAHA-PIP 'G' 
activated the neurogenesis related GPC3 while SAHA-PIP 'P' activated BDNF (Fig. 2E). Interestingly, SAHA-PIP 'W' specifically activated the ataxia related $A T C A Y$ gene (Fig. 2F). ${ }^{109}$ Synthetic PIPs are advantageous over other natural DNA-binding proteins as effective transcriptional activators because they possess flexible covalent sites and can bind to the methylated DNA sequences and disrupt the packed chromatin structure. ${ }^{10}$ Conjugation of a PIP with another HDACi conjugate called JAHA, which is HDAC8 specific also elicited similar promoter specific function. ${ }^{111}$ Thus, it is possible to conjugate HDACis like BML-210, DNMTis like 5-azacytidine, and other such enzyme inhibitors to PIPs to have variable effects. Although it is difficult to predict the off-rate of PIPs inside the cells, the high binding affinity of SAHA-PIP to target DNA sequences and their ability to induce pluripotency genes even at $72 \mathrm{~h}$ and $100 \mathrm{nM}$ concentration suggest it to be slow. ${ }^{112,113}$ Ligands that specifically recognize $15-16$ base pairs like a PIP dimer was shown to target the regulatory region of the HIV-1 genome. ${ }^{114}$ Interestingly, a recent report suggests that partial cellular reprogramming promotes efficient neuroregeneration. ${ }^{115}$ In this regard, development of multi-gene targeting molecules like SAHA-PIPs could aid in the generation of clinically relevant neural cells.

Cell permeability is both an advantage and bottleneck of the PIPs as both the molecular size and pyrrole/imidazole content of the PIPs were shown to hamper its ability to permeate cells. ${ }^{100}$ But recent studies have shown that it is possible to increase the permeability of PIPs by engineering their chemical architecture. ${ }^{116}$ Although PIPs are well characterized to influence gene expression in cell culture, their clinical translation requires comprehensive characterization of their pharmacokinetic (PK) profiles and ADME properties. Fukasawa et al. have shown through intravenous administration of a set of PIPs in rat models, that the area under 
the plasma concentration-time curve increases linearly as a function of dose, and the systemic clearance and the volume distribution in the steady state remain unaltered. ${ }^{117}$ Synold et al. have suggested that size or minor structural modifications of PIPs could affect their solubility and could lead to their accumulation in the lungs. ${ }^{118}$ Although SAHA does not hinder the binding properties of PIPs, it is tough to generalize whether HDACi-PIPs will have the same properties as PIPs. Because the PK profiles and ADME properties of the PIPs showed that various results were obtained with minor changes to the structures, therefore there is the need for a case-by-case study before employing the PIPs and/or HDACi-PIPs.

\subsection{Signalling pathway inhibitors}

The design of innovative small molecules that could effectively modulate intricate signalling factors can be useful to restore cellular homeostasis. Recently, a compound called Fisetin (Fig. 3A) was found to be an orally active, neuroprotective, cognitionenhancing small molecule. Fisetin possesses antioxidant activity and increases the intracellular level of glutathione and it has both neurotrophic and anti-inflammatory activity. ${ }^{119}$ Silivia et al. recently demonstrated CHF5074, a multifunctional antiinflammatory derivative as a novel anti Alzheimer compound in TG2576 mice. ${ }^{120}$ Several synthetic compounds are capable of a synergistic effect on multi-targets associated with a particular signalling pathway. For example, effective inhibitors of acetylcholinesterase (AChE) and Monoamine oxidase such as imino 1, 2, 3, 4tetrahydrocyclopent[b]indole carbamates (Fig. 3B), Coumarin derivatives (Fig. 3C), chromone derivates (Fig. 3D), Lipocrine (Fig. 3E) to i) target the catalytic activity of $\mathrm{AChE}$, ii) inhibit the AChE- induced $A B$ aggregation and iii) to protect against reactive oxygen species (ROS). Likewise, Caproctomine (Fig. 3F) prevented the 
AChE- induced $A ß$ aggregation and stimulated the cholinergic activity by antagonizing the muscarinic $\mathrm{M}_{2}$ receptor. ${ }^{121}$ Bolognesi et al. showed the derivatives of bis-tacrine (Fig. 3G) as the likely candidates for $\mathrm{AD}$ treatment as they could reverse the AChE-induced amyloid fibrillogenesis by inhibiting the AChE activity and chelating the metal ions. ${ }^{122}$ Rosini et al. developed a multi-target directed ligand carbacrine (Fig. $3 \mathrm{H})$ to treat $\mathrm{AD}$ neurodegeneration by effectively blocking the in vitro AChE- induced $\mathrm{A} \beta$ aggregation, decreasing the oxidative stress and antagonizing the NMDA receptor activity. ${ }^{123}$ Memoquin (Fig. 3I) is another multitarget molecule capable of inhibiting acetylcholinesterase and $\beta$-secretase-1activity. Capurro et al. showed that Memoquin could enhance cognition and prevent the A $\beta$ induced neurotoxicity in diseased mouse models. ${ }^{124}$ Youdim et al. prepared multi target drugs Ladostigil (Fig. 3J) and M30 (Fig. 3K), the derivatives of Rasagiline and demonstrated an improved effect on the depression, dementia and behavioral abnormalities related to $\mathrm{AD}$ in mouse models. M30 exhibited the neurorestorative activity and induced the production of BDNF and glia-derived neurotrophic factor. ${ }^{125}$ $\mathrm{Lu}$ et al. have designed and synthesized the derivatives of resveratrol as a candidate for $\mathrm{AD}$ treatment that has the ability to inhibit $\mathrm{A} B$ aggregation. One of the derivatives 5d (Fig. 3L) showed no toxicity in a mouse model and in vitro studies have shown that the drug can enter the blood brain barrier. ${ }^{126}$

Small molecules capable of inhibiting epigenetic enzymes like HDAC and signalling pathway factors can have better efficacy. CUDC-907 is one such compound that has been designed with dual inhibitory activity against not only HDAC enzymes but also phosphatidylinositol 3-kinase (PI3Ks) (Fig. 3M). ${ }^{127}$ When compared with equivalent single target molecules, CUDC-907 displayed better growth inhibition in both cultured and implanted cancer cells by inhibiting class I and 
II HDAC enzymes as well as the PI3K-AKT-mTOR pathway and signaling molecules (including MEK, RAF (a protein oncogene protein kinase), STAT-3 (Signal transducer and activator of transcription), and MAPK (Mitogen activate protein kinase)) and the upstream receptor tyrosine kinases. Developing such dual inhibitory small molecules could be useful in recovering memory and alleviating neurodegeneration.

(Fig. 3)

\section{Conclusion and future perspective}

Small molecules are often referred to as the missing link in the central dogma of biology. ${ }^{1}$ Recent developments in bioinformatics and techniques such as diversityoriented synthesis suggest that it is possible to design small molecules to treat the diseases that were previously thought to be incurable. In general, diseases are characterized by dysregulation in the transcriptional machinery that maintains the cellular homeostasis. LTP governs a multitude of brain functions such as learning and memory. Small molecules that alter the chromatin architecture and signal transduction have shown clinical potential to modulate LTP mechanisms. However, to achieve effective regulation, artificial transcriptional activators capable of orchestrating a target gene network need to mimic its natural equivalents. By taking cues from nature, development of novel types of compounds like HDAC-PIPs, CUDC-907, CHF5074 and others (Fig. 3) could open up exciting opportunities to precisely orchestrate the intricate transcriptional machinery conferring to memory. However, precaution should be taken to develop such strategies because chromatin remodelling and signalling pathways are not secluded events. Moreover, factors such as practicality and genome-wide specificity need to be focused to avoid side effects. Drugability is 
another major factor that needs consideration, as physicochemical characteristics, DMPA properties and safety profiles of these multi-target molecules could hamper the development of such molecules. Strategies to make the sequence-specific epigenetic activators and/or signalling inhibitors to penetrate CNS are another major issues that need profound study. Some of the factors such as target-target interactions, different requirements for the percentage and duration of target engagement for different targets should also be considered. Because interaction of one target could affect the signaling of another target, while the activation/inhibition of multiple targets could result in synergic toxic effects. Innovative strategies to generate multitarget molecules with tunable activation potentials of differing strengths by taking the above-mentioned factors into account can lead to effective treatment of complex neurological disorders as illustrated in Fig. 4.

(Fig. 4)

\section{Acknowledgements}

This research was supported by the Ministry of Education, Culture, Sports, Science and Technology (MEXT) of Japan. The iCeMS is supported by World Premier International Research Center Initiative, MEXT, Japan. We thank Nagase Science and Technology foundation for their support. We thank Grants-in-aid for Young Scientists-B and challenging exploratory research for support to G. N. P.

\section{References}

1. S. L. Schreiber, Nat. Chem. Biol., 2005, 1, 64-66.

2. A. L. Hopkins, and C. R. Groom, Nat. Rev. Drug Discov., 2002, 1, 727-730.

3. D. B. Matthew, C. Raymond, and L. Andre, Science, 2012, 338, 334-335.

4. D. Baltimore, Nature, 2001, 409, 814-816. 
5. J. Cortés-Mendoza, S. Díaz de León-Guerrero, G. Pedraza-Alva, and L. PérezMartínez, Int. J. Dev. Neurosci., 2013, 31, 359-369.

6. I. Winkler, and N. Cowan, Exp. Psychol., 2004, 51, 1-17.

7. P.E. Gold, Neurobiol. Learn Mem., 2008, 89, 201-211.

8. R. C. Malenka, and R. A. Nicoll, Science, 1999, 285, 1870-1874.

9. M. A. Lynch, Physiol. Rev., 2004, 84, 87-136.

10. M. J. Morris, and L. M. Monteggia, Int. J. Dev. Neurosci., 2013, 31, 370-381.

11. C. G. Vecsey, J. D. Hawk, K. M. Lattal, J. M. Stein, S. A. Fabian, M. A. Attner, S. M. Cabrera, C. B. McDonough, P. K. Brindle, T. Abel, and M. A. Wood, J. Neurosci., 2007, 27, 6128-6140.

12. A. Suzuki, H. Fukushima, T. Mukawa, H. Toyoda, W. Long-Jun, Z. Ming-Gao, H. Xu, Y. Shang, K. Endoh, T. Iwamoto, N. Mamiya, E. Okano, S. Hasegawa, V. Mercaldo, Y. Zhang, R. Maeda, M. Ohta, , S. A. Josselyn, M. Zhuo, , and S. Kida, Neurosci., 2011, 31, 8786 -8802.

13. J. Haetig, D. P. Stefanko, M. L. Multani, D. X. Figueroa, S. C. McQuown, and M. A. Wood, Learn Mem., 2011, 18, 71-79.

14. C. M. Alberini, Physiol. Rev., 2009, 89, 121-145.

15. M. A. Wood, J. D. Hawk, and T. Abel, Learn Mem., 2006, 13, 241-244.

16. Z. Guan, M. Giustetto, S. Lomvardas, J. H. Kim, M. C. Miniaci, J. H. Schwartz, D. Thanos, and E. R. Kandel, Cell, 2002, 111, 483-493.

17. A. B. Danilova, and L. N. Grinkevich, 2012, PLoS ONE, 7: e41828.

18. T. R. Mercer, M. E. Dinger, J. Mariani, K. S. Kosik, M. F. Mehler, and J. S. Mattick, Neuroscientist, 2008, 14, 434-445.

19. G. Barry, Mol. Psychiatr., 2014, 19, 410-416.

20. X. Cao, G. Yeo, A. R. Muotri, T. Kuwabara, and F. H. Gage, Annu. Rev. 
Neurosci., 2006, 29, 77-103.

21. H.L. Scott, F. Tamagnini, K.E. Narduzzo, J.L. Howarth, Y. B. Lee, L. F. Wong, M.W. Brown, E. C. Warburton, Z. I. Bashir, and J. B. Uney, Eur. J. Neurosci., 2012, 36, 2941-2948.

22. D. H. Joshua, L. B. Angie, G. P. Shane, B. Morgan, J. R. Allison, E. S. Michael, T. K. Brian, J. M. David, and T. Abel, J. Clin. Invest., 2012, 122, 3593-3602.

23. A. Fischer, F. Sananbenesi, X. Wang, M. Dobbin, and L. H. Tsai, Nature, 2007, 447, 178-182.

24. C. S. Ramóny, Proc. Roy. Soc. Lond. B, 1894, 55, 444-468.

25. D. O. Hebb, Organization of Behavior: a Neuropsychological Theory. John Wiley, New York. 1949

26. T. Bliss, and T. Lømo, J. Physiol., 1973, 232, 331-356.

27. R. M. Douglas, and G. V. Goddard, Brain Res., 1975, 86, 205-215.

28. R. Malenka, and M. Bear, Neuron, 2004, 44, 5-21.

29. H. Yasuda, A. Barth, D. Stellwagen, and R. Malenka, Nat. Neurosci., 2003, 6, $15-16$.

30. W. C. Abraham, Philos. Trans. R. Soc. Lond. B: Biol. Sci., 2003, 358, 735-744.

31. T. V. P. Bliss, G. L. Collingridge, and S. Laroche, Science, 2006, 313, 10581059.

32. T. C. Sacktor, Mol. Brain., 2012, 5, 31.

33. M. W. Jones, M. L. Errington, P. J. French, A. Fine1, T. V. P. Bliss, S. Garel, P. Charnay, B. Bozon, S. Laroche, and S. Davis, Nat. Neurosci., 2001, 4, 289-296.

34. J. R. Whitlock, A. J. Heynen, M. G. Shuler, and M. F. Bear, Science, 2006, 313, 1093- 1097.

35. M. Goedert, and M. G. Spillantini, Science, 2006, 314, 777-781. 
36. G. M. Shankar, S. Li, T. H. Mehta, A. Garcia-Munoz, N. E. Shepardson, I. Smith, F. M. Brett, M. A. Farrell, M. J. Rowan, and C. A. Lemere, Nat. Med., $2008,14,837-842$.

37. J. F. Crary, C. Y. Shao, S. S. Mirra, A. I. Hernandez, and T. C. Sacktor, J. Neuropathol. Exp. Neurol., 2006, 65, 319-326.

38. K. Lunnon and J. Mill, Am. J. Med. Genet. B. Neuropsychiatr. Genet., 2013, 162, 789-799.

39. J. Gräff, D. Rei, J. S. Guan, W. Y. Wang, J. Seo, K. M. Hennig, T. J. Nieland, D. M. Fass, P. F. Kao, M. Kahn, S. C. Su, A. Samiei, N. Joseph, S. J. Haggarty, I. Delalle, and L.H. Tsai, Nature, 2012, 483, 222-226

40. D. Crupi, M. F. Ghilardi, C. Mosiello, A. D. Rocco, A. Quartarone, and F. Battaglia, Brain Res. Bulletin, 2008, 75, 107-114.

41. G. M. Dallérac, S. C. Vatsavayai, D. M. Cummings, A. J. Milnerwood, C. Peddie, J., K. A. Evans, S. W. Walters, P. Rezaie, M. C. Hirst, and K. P. Murphy, Neurodegener. Dis., 2011, 8, 230-239.

42. C. Costa, C. Sgobio, S. Siliquini, A. Tozzi, M. Tantucci, V. Ghiglieri, , M. Di Filippo, V. Pendolino, A. de Iure, M. Marti, M.Morari, M. G.Spillantini, E. C. Latagliata, T. Pascucci, S. Puglisi-Allegra, F. Gardoni, M. Di Luca, B. Picconi, and P. Calabresi, Brain, 2012, 135, 1884-1899.

43. J. M. Gil and A. C. Rego, Eur. J. Neurosci., 2008, 27, 2803-2820.

44. Y. Watanabe, S. Kameoka, V. Gopalakrishnan, K. D. Aldape, Z. Z, Pan, F. F. Lang, and S. Majumder, Genes Dev., 2004, 18, 889-900.

45. T. Vierbuchen, A. Ostermeier, Z. P. Pang, Y. Kokubu, T. C. Südhof, and M. Wernig, Nature, 2010, 463, 1035-1041.

46. A. G. Xuan, M. Luo, W. D. Ji, and D. H. Long, Neurosci. Lett., 2009, 450, $167-$ 
171.

47. M. Blurton-Jones, M. Kitazawa, H. Martinez-Coria, N. A. Castello, F. J. Muller, J. F. Loring, T. R. Yamasaki, W. W. Poon, K. N. Green, and F. M. LaFerla, Proc. Natl. Acad. Sci. USA. 2009,106,13594-13599.

48. L. Minichiello, Nat. Rev. Neurosci., 2009, 10, 850-860.

49. K. Baumgärtel, D. Genoux, H. Welzl, R. Y. Tweedie-Cullen, K. Koshibu, M. Livingstone-Zatchej, C. Mamie, and I. M. Mansuy, Nat. Neurosci., 2008, 11, $572-578$

50. C. R. Bramham, P. F. Worley, M. J. Moore, and J. F. Guzowski, J. Neurosci., 2008, 28, 11760-11767.

51. M. M. Ryan, B. Ryan, M. Kyrke-Smith, B. Logan, W. P. Tate, W. C. Abraham, and J. M. Williams, PLoS ONE, 2012, 7, e40538.

52. U. Beffert, E. J. Weeber, A. Durudas, S. Qiu, I. Masiulis, J. D. Sweatt, L. WeiPing, G. Adelmann, M. Frotscher, R. E. Hammer, and J. Herz, Neuron, 2005, 47, $567-579$.

53. M. A. Lynch, K. L. Voss, J. Rodriguez, and T. V. Bliss, Neurosci., 1994, 60, 15

54. J. Li, C. Chen, C. Chen, Q. He, and H. Li, PLoS ONE, 2011, 6, e17365.

55. P. Tarpey, J Parnau, M. Blow, H. Woffenndin, G. Bignell, C. Cox, J. Coc, H. Davies, S. Edkins, S. Holden, A. Korny, U. Mallya, J. Moon, S. Omeara, A. Parker, and P. Stephens, Am. J. Hum. Genet., 2004, 75, 318-324.

56. A. M. Huang, H.L. Wang, Y.P. Tang, and E. H. Lee, J. Neurosci., 1998, 18, $4305-4313$

57. J. Gräff, and I. M. Mansuy. Behav. Brain Res., 2008, 192, 70-87.

58. J. J. Day, and J.D. Sweatt, Neurobiol. Learn Mem., 2011, 96, 2-12.

59. V. Yuferov, D. A. Nielsen, O. Levran, M. Randesi, S. Hamon, A. Ho, S. 
Morgello, and M. J. Kreek, Pharmacogenet. Genomics, 2011, 21, 185-196.

60. F. D. Lubin, T. L. Roth, and J. D. Sweatt, J. Neurosci., 2008, 28, 10576-10586.

61. J. Feng, Y. Zhou, S.L. Campbell, T. Le, E. Li, J.D. Sweatt, A.J. Silva, and G.Fan, Nat. Neurosci., 2010, 13, 423-430.

62. J. J. Day, J. D. Sweatt, Neuropsychopharmacology, 2012, 37, 247-260

63. C. A. Miller, and J. D. Sweatt, Neuron, 2007, 15, 857-869.

64. P. A. Jones, and S. B. Baylin, Nat. Rev. Genet., 2002, 3, 415-428.

65. J. P. Lopez-Atalaya, S. Ito, L. M. Valor, E. Benito, and A. Barco, A. Nucleic Acids Res., 2013, 41, 8072-8084.

66. L. J. Juan, W. J. Shia, M.H. Chen, W. M. Yang, E. Seto, Y.S. Lin, and C.W. Wu, J. Biol. Chem., 2000, 275, 20436-20443.

67. W. G. Zhu, R. R. Lakshmanan, M. D. Beal, and G. A. Otterson, Cancer Res., 2001, 61, 1327-1333.

68. J. Hsieh, K. Nakashima, and T. Kuwabara, Proc. Natl. Acad. Sci. USA., 2004, 101, 16659-16664.

69. Z. Gao, K. Ure, and J. L. Ables, Nat. Neurosci., 2009, 12, 1090-1092.

70. I. T. Yu, J. Y. Park, and S. H. Kim, Neuropharmacol., 2009, 56, 473-480.

71. S. Jessberger, K. Nakashima, and G. D. Clemenson, J. Neurosci., 2007, 27, $5967-5975$

72. H. J. Kim, P. Leeds, and D. M. Chuang, J. Neurochem., 2009, 110, 1226-1240.

73. A. Contestabile, S. Sintoni, and B. Monti, Curr. Psychopharmacol., 2012, 1, $14-28$.

74. C. M. Alberini, Physiol. Rev., 2009, 89, 121-145.

75. D. P. Stefanko, R. M. Barrett, A. R. Ly, G. K. Reolon, and M. A. Wood, Proc. Natl. Acad. Sci. USA., 2009, 106, 9447-9452. 
76. J. S. Guan, S. J. Haggarty, E. Giacometti, J. H. Dannenberg, N. Joseph, J. Gao, T. J. Nieland, Y. Zhou, X. Wang, and R. Mazitschek, Nature, 2009, 459, 55-60.

77. S. C. McQuown, R. M. Barrett, D. P. Matheos, R. J. Post, G. A. Rogge, T. Alenghat, S. E. Mullican, S. Jones, J. R. Rusche, and M. A. Lazar, J. Neurosci., 2011, 31, 764-774.

78. G. Faraco, T. Pancani, L. Formentini, P. Mascagni, G. Fossati, F. Leoni, F. Moroni, and A. Chiarugi, Mol Pharmacol., 2006, 70, 1876-1884.

79. M. Malvaez, S. C. McQuowna, G. A. Roggea, M. Astarabadia, V. Jacquesc, S. Carreiroc, J. R. Ruschec, and M. A. Wood, Proc. Natl. Acad. Sci. USA, 2013, 110, 2647-2652.

80. R. J. Ferrante, J. K. Kubilus, J. Lee, H. Ryu, A. Beesen, B. Zucker, K. Smith, N. W. Kowall, R. R. Ratan, R. Luthi-Carter, and S. M. Hersch, J. Neurosci., 2003, 23, 9418-9427.

81. P. Chiurazzi, M. G. Pomponi, R. Pietrobono, C. E. Bakker, G. Neri, and B. A. Oostra, Hum. Mol. Genet., 1999, 8, 2317-2323.

82. H. M. Amir, and C. Frédéric, J. Mol. Biol., 2011, 409, 758-772.

83. G. Lynch, C. S. Rex, and C. M. Gall, Ageing Res. Rev., 2006, 5, 255-80.

84. J. Gräff, and L-H. Tsai, Annu. Rev. Pharmacol. Toxicol., 2013, 53, 331-330.

85. S. Sintoni, E. Kurtys, M. Scandaglia, A. Contestabile, B. Monti, Pharmacol. Biochem. Behav., 2013, 106, 8-15.

86. C. T. Gualtieri, L. G. Johnson, K. B. Benedict, J. Neuropsychiatry. Clin. Neurosci., 2006, 18, 217-225.

87. C. Hommet, K. Mondon, B. de Toffol, T. Constans, J. Am. Geriatr. Soc., 2007, 55,628 .

88. E. T. Kavalali, E. D. Nelson, and L. M. Monteggia, J. Neurodev. Disord., 2011, 
3, 250-256.

89. M. Adachi, A. E. Autry, H. E. Covington, and L. M. Monteggia, J. Neurosci., 2009, 29, 4218-4227.

90. V. Campuzano, L. Montermini, M. D. Molto, L. Pianese, M. Cossee, F. Cavalcanti, E. Monros, F. Rodius, F. Duclos, A. Monticelli, F. Zara, J. Canizares, H. Koutnikova, S. I. Bidichandani, C. Gellera, A. Brice, P. Trouillas, G. D. Michele, A. Fila, R. D. Frutos, F. Palau, P. I. Patel, S. D. Donato, J. L. Mandel, S. Cocozza, M. Koenig, M. Pandolfo, Science, 1996, 271, 1423-1427

91. M. Rai, E. Soragni, C. J. Chou, G. Barnes, S. Jones, J. R. Rusche, J. M. Gottesfeld, and M. Pandolfo, PLoS One, 2010, 5, e8825.

92. T. Abel, and R. S. Zukin, Curr. opin. Pharmacol., 2008, 8, 57-64.

93. K. L. Sugars, and D. C. Rubinsztein, Trends Genet., 2003, 19, 233-238.

94. J. S. Steffan, L. Bodai, J. Pallos, M. Poelman, A. McCampbell, B. L. Apostol, A. Kazantsev, E. Schmidt, Y. Z. Zhu, M. Greenwald, R. Kurokawa, D. E. Housman, G. R. Jackson, J. L. Marsh, and L. M. Thompson, Nature, 2001, 413, 739-743.

95. G. Gardian, S. E. Browne, D. K. Choi, P. Klivenyi, J. Gregorio, J. K. Kubilus, H. Ryu, B. Langley, R. R. Ratan, R. J. Ferrante, and M. F. Beal, J. Biol. Chem., 2005, 280, 556-563.

96. E. Hockly, V. M. Richon, B. Woodman, D. L. Smith, X. Zhou, E. Rosa, K. Sathasivam, S. Ghazi-Noori, A. Mahal, P. A. Lowden, J. S. Steffan, J. L. Marsh, L. M. Thompson, C. M. Lewis, P. A. Marks, and G. P. Bates, Proc. Natl. Acad. Sci. USA., 2003, 100, 2041-2046.

97. E. A. Thomas, G. Coppola, P. A. Desplats, B. Tang, E. Soragni, R. Burnett, F. Gao, K. M. Fitzgerald, J. F. Borok, D. Herman, D. H. Geschwind, and J. M. 
Gottesfeld, Proc. Natl. Acad. Sci. U. S. A., 2008, 105, 15564-15569.

98. M. Beconi, O. Aziz, K. Matthews, L. Moumné, C. O’Connell, D. Yates, S. Clifton, H. Pett, J. Vann, L. Crowley, A. F. Haughan, D. L. Smith, B. Woodman, G. P. Bates, F. Brookfield, R. W. Bürli, G. McAllister, C. Dominguez, I. Munoz-Sanjuan, and V. Beaumont, PLoS One, 2012, 7. e44498.

99. G. Kashiwazaki, T. Bando, T. Yoshidome, S. Masui, T. Takagaki, K. Hashiya, G. N. Pandian, J. Yasuoka, K. Akiyoshi, and H. Sugiyama, J. Med. Chem., 2012, 55, 2057-2066.

100. G. N. Pandian and H. Sugiyama, Biotechnol J, 2012, 7, 798-809.

101. R. D. Taylor, S. Asamitsu, T. Takenaka, M. Yamamoto, K. Hashiya, Y. Kawamoto, T. Bando, H. Nagase, and H. Sugiyama, Chem. - A Eur. J., 2013, 19, $1-9$

102. R. Burnett, C. Melander, J. W. Puckett, L. S. Son, R. D. Wells, P. B. Dervan, and J. M. Gottesfeld, Proc. Natl. Acad. Sci. U. S. A., 2006, 103, 11497-11502.

103. D. M. Chenoweth, J. L. Meier, and P. B. Dervan, Angew. Chem. Int. Ed. Engl., $2013, \mathbf{5 2}, 415-418$.

104. A. Ohtsuki, M. T. Kimura, M. Minoshima, T. Suzuki, M. Ikeda, T. Bando, H. Nagase, K. ichi Shinohara, and H. Sugiyama, Tetrahedron Lett., 2009, 50, $7288-7292$.

105. G. N. Pandian, K. Shinohara, A. Ohtsuki, Y. Nakano, M. Masafumi, T. Bando, H. Nagase, Y. Yamada, A. Watanabe, N. Terada, S. Sato, H. Morinaga, and H. Sugiyama, Chembiochem, 2011, 12, 2822-2828.

106. G. N. Pandian, A. Ohtsuki, T. Bando, S. Sato, K. Hashiya, and H. Sugiyama, Bioorg. Med. Chem., 2012, 20, 2656-2660.

107. G. N. Pandian, Y. Nakano, S. Sato, H. Morinaga, T. Bando, H. Nagase, and H. 
Sugiyama, Sci. Rep., 2012, 2. e544

108. L. Han, G. N. Pandian, S. Junetha, S. Sato, C. Anandhakumar, J. Taniguchi, A. Saha, T. Bando, H. Nagase, and H. Sugiyama, Angew. Chem. Int. Ed. Engl., 2013, 52, 13410-13413.

109. G. N. Pandian, J. Taniguchi, S. Junetha, S. Sato, L. Han, A. Saha, C. AnandhaKumar, T. Bando, H. Nagase, T. Vaijayanthi, R. D. Taylor, and H. Sugiyama, Sci. Rep., 2014, 4, e3843

110. G. N. Pandian and H. Sugiyama, Pharmaceuticals, 2012, 6, 1-24.

111. A. Saha, G. N. Pandian, S. Sato, J. Taniguchi, K. Hashiya, T. Bando, and H. Sugiyama, Bioorg. Med. Chem., 2013, 21, 4201-4209.

112. T. Vaijayanthi, T. Bando, G. N. Pandian, and H. Sugiyama, Chembiochem, $2012, \mathbf{1 3}, 2170-2185$.

113. T. Vaijayanthi, T. Bando, K. Hashiya, G. N. Pandian, and H. Sugiyama, Bioorg. Med. Chem., 2013, 21, 852-855.

114. J. W. Trauger, E. E. Baird, and P. B. Dervan, J. Am. Chem. Soc. 1998. 120, $3534-3535$

115. T. Matsui, M. Takano, K. Yoshida, S. Ono, C. Fujisaki, Y. Matsuzaki, Y. Toyama, M. Nakamura, H. Okano, and W. Akamatsu, Stem Cells, 2012, 30, $1109-1119$.

116. J. L. Meier, D. C. Montgomery, and P. B. Dervan, Nucleic Acids Res., 2012, 40, $2345-2356$.

117. A. Fukasawa, T. Aoyama, T. Nagashima, N. Fukuda, T. Ueno, H. Sugiyama, H. Nagase, and Y. Matsumoto, Biopharm. Drug Dispos., 2009, 30, 81-89.

118. T. W. Synold, B. Xi, J. Wu, Y. Yen, B. C. Li, F. Yang, J. W. Phillips, N. G. Nickols, and P. B. Dervan, Cancer Chemother. Pharmacol., 2012, 70, 617-625. 
119. C. Chiruta, D. Schubert, R. Dargusch, and P. Maher, J. Med. Chem., 2012, 55, $378-389$.

120. S. Sivilia, L. Lorenzini, A. Giuliani, M. Gusciglio, M. Fernandez, V. A. Baldassarro, C. Mangano, L. Ferraro, V. Pietrini, M. F. Baroc, A. R. Viscomi, S. Ottonello, G. Villetti, B. P. Imbimbo, L. Calzà, and L. Giardino, BMC Neurosci., 2013, 14, 44.

121. H. Y. Zhang, FEBS Lett., 2005, 579, 5260-5264.

122. M. L. Bolognesi, A. Cavalli, L. Valgimigli, M. Bartolini, M. Rosini, V. Andrisano, M. Recanatini, and C. Melchiorre, J. Med. Chem., 2007, 50, 64466449.

123. M. Rosini, E. Simoni, M. Bartolini, A. Cavalli, L. Ceccarini, N. Pascu, D. W. McClymont, A. Tarozzi, M. L. Bolognesi, A. Minarini, V. Tumiatti, V. Andrisano, I. R. Mellor, and C. Melchiorre, J. Med. Chem., 2008, 51, 43814384.

124. V. Capurro, P. Busquet, J. P. Lopes, R. Bertorelli, G. Tarozzo, M. L. Bolognesi, D. Piomelli, A. Reggiani, and A. Cavalli, PLoS One, 2013, 8. e56870.

125. M. B. H. Youdim, Exp. Neurobiol., 2013, 22, 1-10.

126. C. Lu, Y. Guo, J. Yan, Z. Luo, H.-B. Luo, M. Yan, L. Huang, and X. Li, J. Med. Chem., 2013, 56, 5843-5859.

127. C. Qian, C.-J. Lai, R. Bao, D.-G. Wang, J. Wang, G.-X. Xu, R. Atoyan, H. Qu, L. Yin, M. Samson, B. Zifcak, A. W. S. Ma, S. DellaRocca, M. Borek, H.-X. Zhai, X. Cai, and M. Voi, Clin. Cancer Res., 2012, 18, 4104-4113. 


\section{Graphical Abstract}

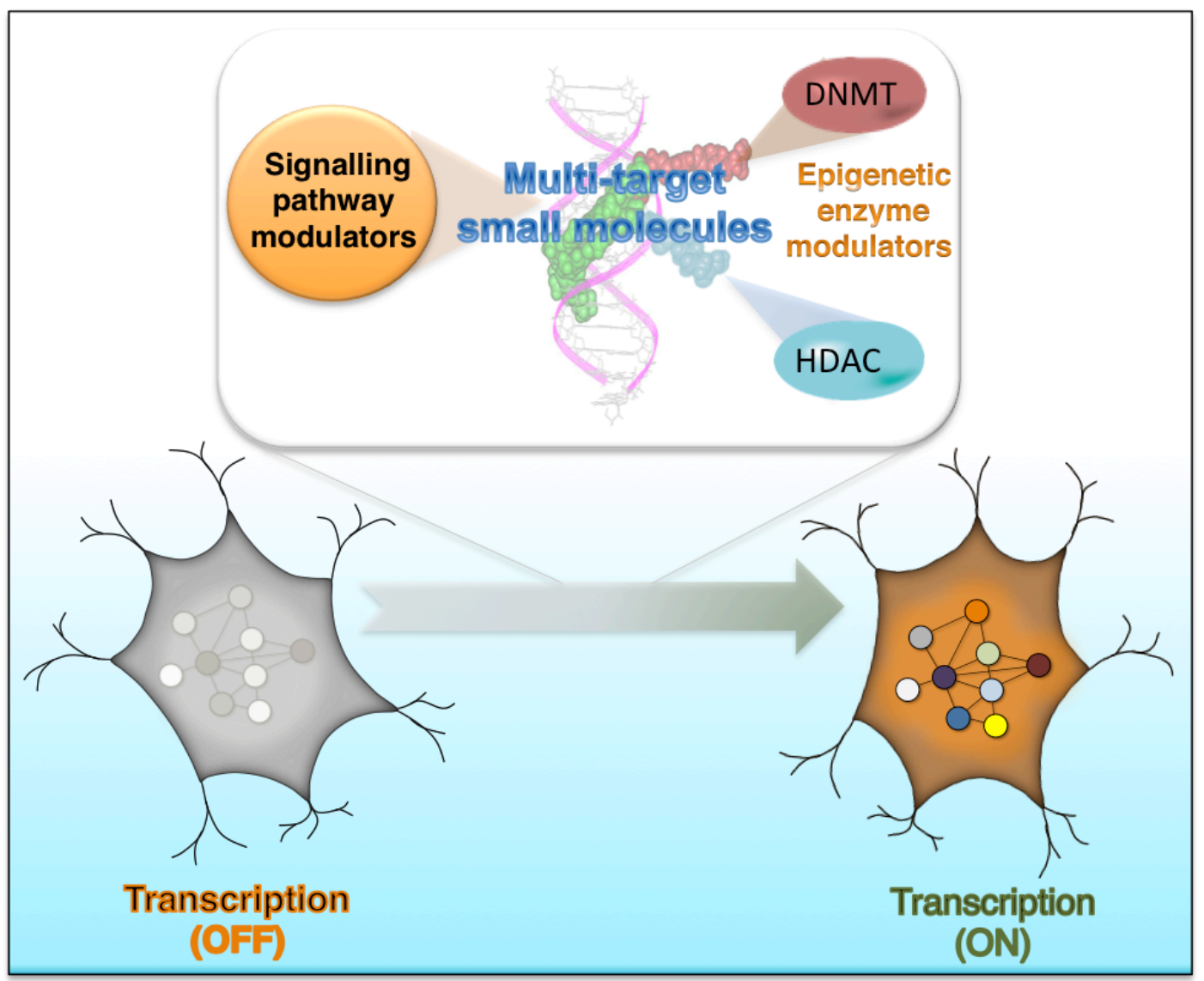

Next-generation synthetic genetic ON switches: Sequence-specific small molecules capable of modulating epigenetic enzymes like DNA methyl transferase (DNMT), histone deacetylases (HDAC) and signalling pathway factors can precisely turn ' $\mathrm{ON}^{`}$ the multi-gene network in a neural cell. 


\section{Author Biographies}

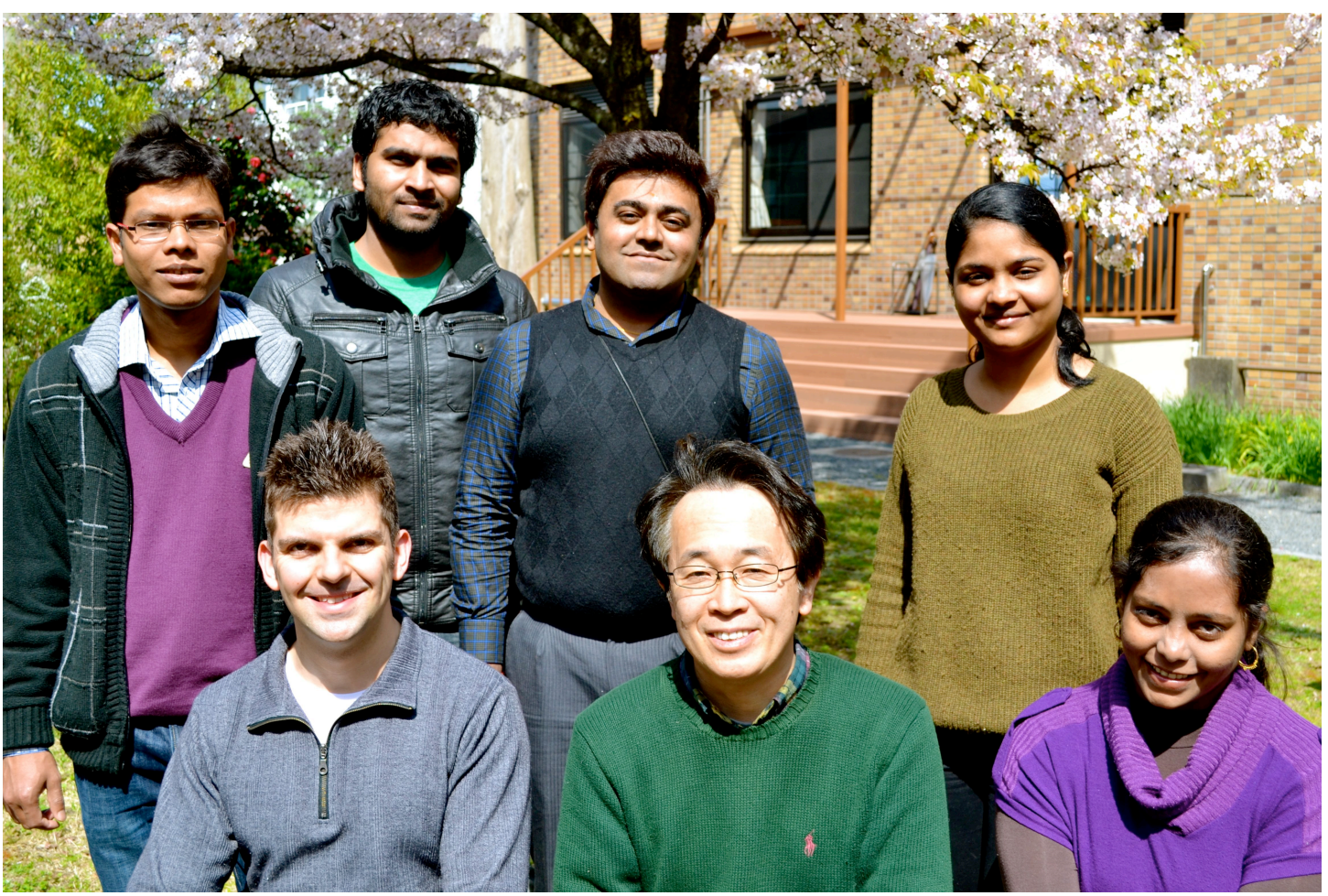

(From Left to right) - Abhijit Saha, Anandhakumar Chandran, Ganesh N Pandian, Syed Junetha; Seated (Left to right) - Rhys D. Taylor, Hiroshi Sugiyama, Vaijayanthi Thangavel)

Ganesh N. Pandian received his PhD in Biotechnology in 2009 from Niigata University with Monbukagakusho (Japanese Government) scholarship under the guidance of Prof. Hidetaka Hori. He continued his research with Prof. Hori as Assistant Professor (Research). Since 2010, he has been working at Institute for Integrated CellMaterial Sciences (WPI-iCeMS) Kyoto University as Research Associate with Prof. Hiroshi Sugiyama to develop artificial genetic switches for stem cell control.

Rhys D. Taylor received his Masters in Chemisty from the University of Manchester, United Kingdom. He is currently a doctoral student in Sugiyama Lab, Kyoto University. His research work focuses on the development of Pyrrole-imidazole polyamide conjugates for selective gene suppression.

Junetha Syed graduated with her master degree in Microbial gene Technology from MaduraiKamaraj University, India, in 2009. Later, she joined as a Project Associate in the Department of Biotechnology, Indian Institute of Technology,Madras and her research focus was on Cancer biology. She is now a doctoral student under the guidance of Prof. Hiroshi Sugiyama in the Department of Chemistry, Kyoto University and her research interest is on the epigenetics in cancer

AnandhaKumar Chandran received his Masters in Marine Genomics from MaduraiKamaraj University, India. Then, he Joined as a Senior Research Fellow in Madras Veterinary College. Now, he joined Professor Sugiyama's Chemical Biology group of Kyoto University as a Doctoral student and studying on global gene expression profile in small molecule-mediated cellular reprogramming.

Abhijit Saha received his master in organic chemistry from Cotton College, India in 2008. He joined Indian Institute of Technology Guwahati in 2009 as a Junior Research Fellow, worked on peptide synthesis. Now he is a doctoral course student in Prof Sugiyama Group. His research interest is synthesis and biological evaluation of small molecules for epigenetic control. 
Vaijayanthi Thangavel obtained her PhD in Chemistry at the Indian Institute of Technology-Madras, Chennai, India in 2008 under the supervision of Prof. Anju Chadha. She then conducted post-doctoral research in the group of Prof. Andreas S. Bommarius at the Georgia Institute of Technology, Atlanta, USA. She continued her research as special assistant professor (Research) in the group of Prof Hori Hidetaka, Niigata University, Japan. Since 2011 she has been doing her postdoctoral research with Prof Hiroshi Sugiyama, Kyoto University on the development and applications of Pyrrole-imidazole polyamide-fluorophore conjugates.

Hiroshi Sugiyama received his PhD in 1984, studying under Teruo Matuura at Kyoto University. After postdoctoral studies at the University of Virginia with Sidney M. Hecht, he returned to Kyoto University in 1986 as Assistant Professor and became Associate Professor in 1993. In 1996, he joined the Institute of Biomaterials and Bioengineering at Tokyo Medical and Dental University as Professor. He has been Professor of chemical biology at Kyoto University since 2003. Among the honors he has received are the Nippon IBM Award and the Chemical Society of Japan Award for Creative Work. 


\section{Figure 1}
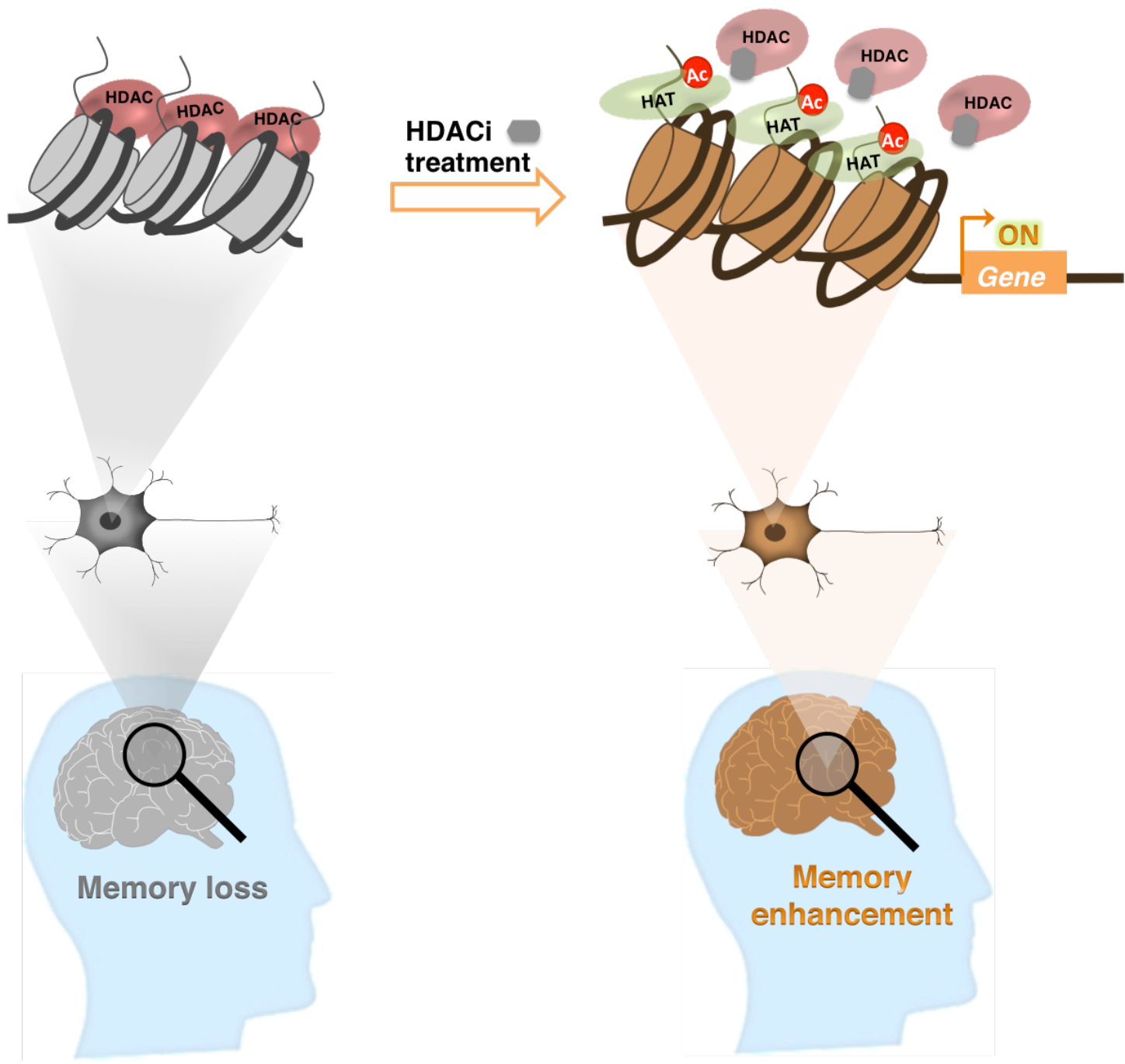

Fig. 1. A person with memory loss (Brain and neuron in grey) has a heterochromatin architecture protected by HDAC in which memory-associated gene(s) are silenced. HDACi treatment improves the memory (Brain and neuron in orange) through chromatin remodeling (acetylation in histones (colored)). 
Figure 2

A) Selective DNA binding PIPs

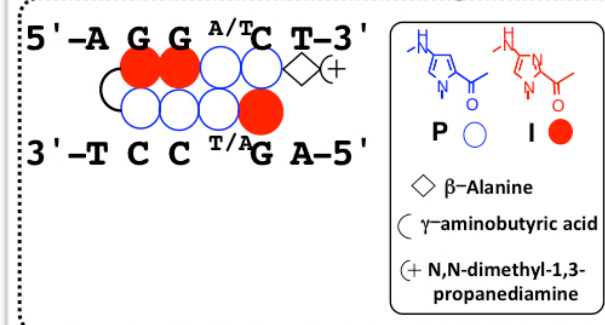

Epigenetically active SAHA

SAHA-PIP

CO000

SAHA

B) Mouse fibroblasts
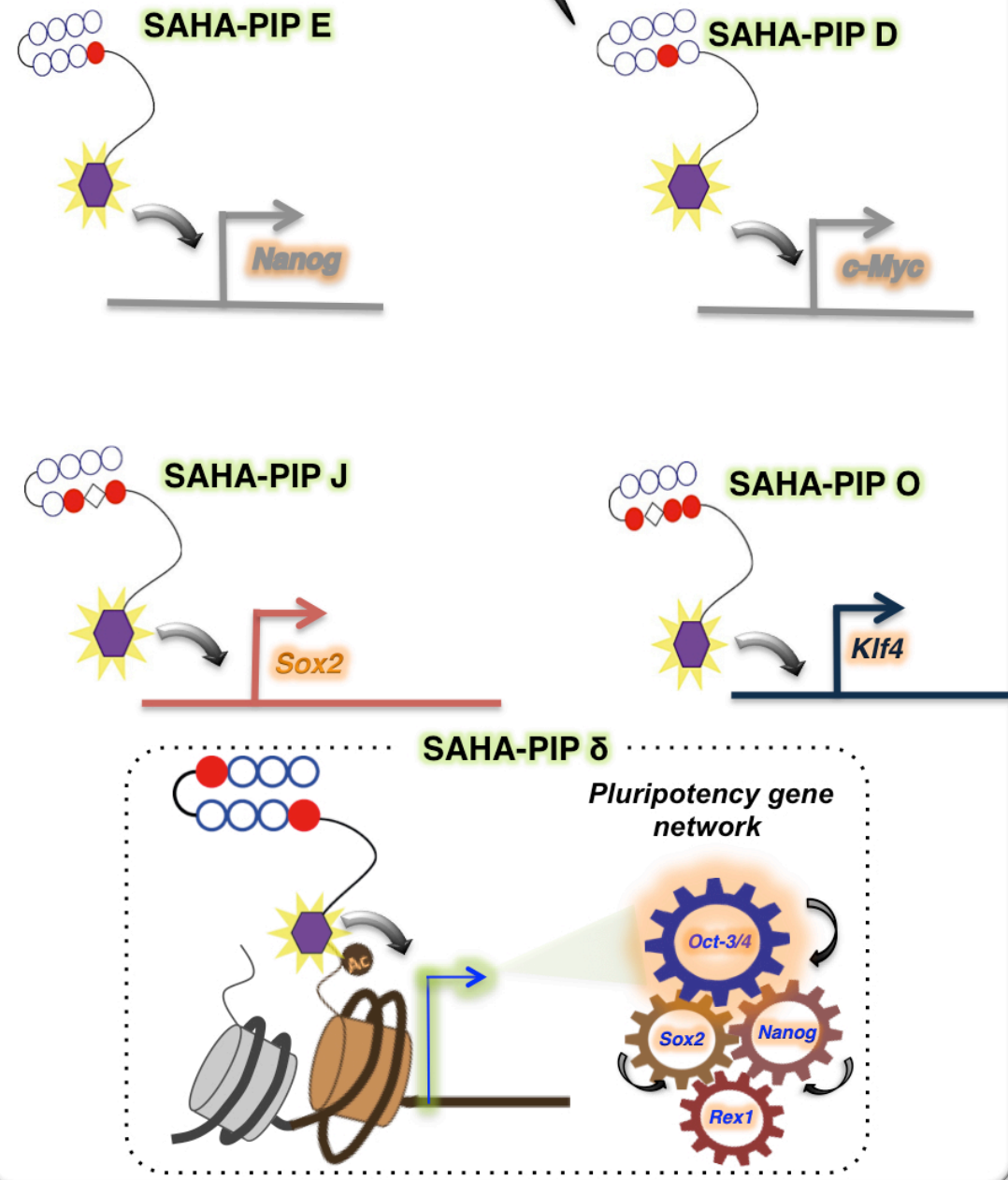
C) Human filbroblasts
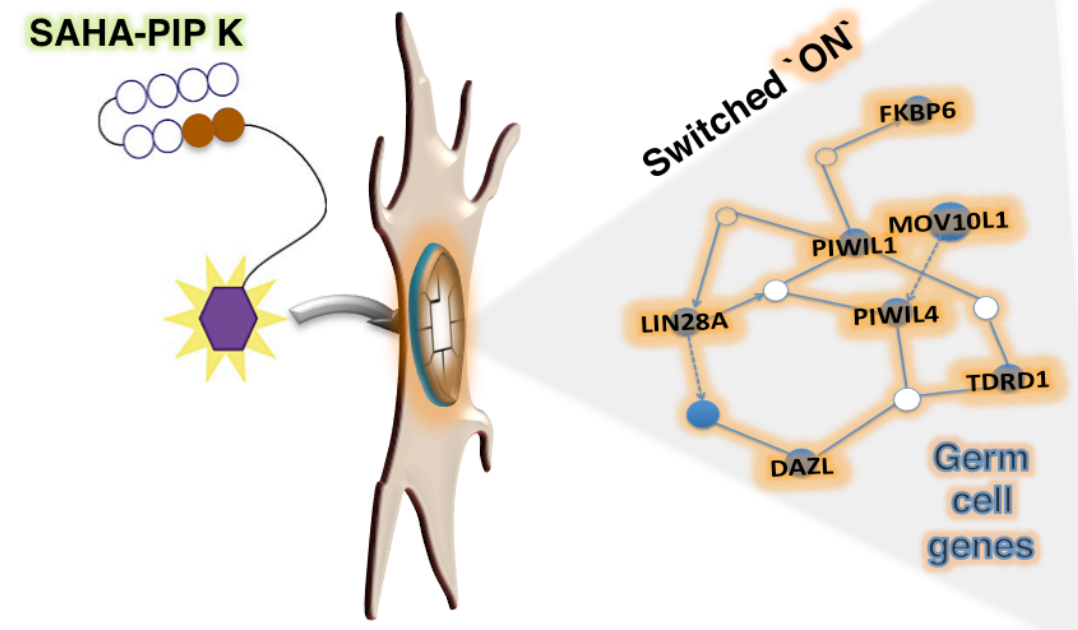

D) SAHA-PIP M

E) SAHA-PIP G

SAHA-PIP P
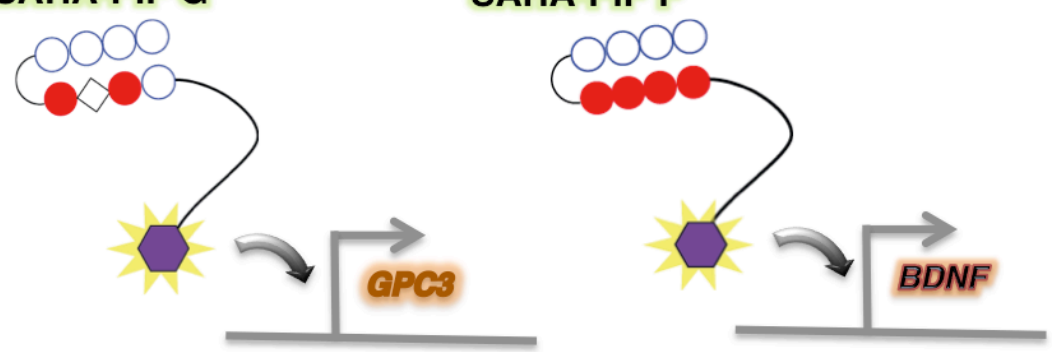

F) SAHA-PIP W

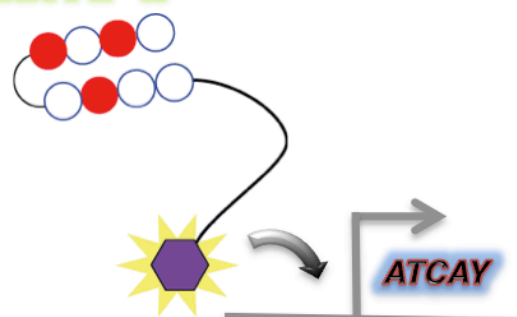


Fig. 2. (A) Creation of a DNA-based epigenetic switch. An innovative small molecule called SAHA-PIP capable of accessing both genetic and epigenetic environment got achieved by conjugating sequence-specific hairpin pyrrole imidazole polyamides (PIPs) with chromatin modifying histone deacetylases inhibitor SAHA. (B) Biological activity of SAHA-PIP in mouse cells. SAHA-PIP E could cause site-specific acetylation by hindering the HDACs only in the promoter of Nanog in mouse fibroblasts. SAHA-PIPs D, J and O for $c-M y c$, Sox2 and Klf4 is also shown. Advanced version of SAHA-PIP $\delta$ induces site-specific chromatin remodelling of Oct-3/4 to trigger the core pluripotency gene network. (C) Biological activity of SAHA-PIP in human cells. SAHA-PIP K trigger unusual switching ON of the germ cell genes in a human somatic cell. (D) SAHA-PIP M trigger neurotransmitter related gene network. (E) SAHA-PIP G and P trigger neurogenesis related genes (GPC3 and $B D N F$ ) and (F) SAHA-PIP W trigger for Ataxia related $A T C A Y$ gene. 
Figure 3

A)<smiles>O=c1c(O)c(-c2ccc(O)c(O)c2)oc2cc(O)ccc12</smiles>

\section{Fisetin}

(COX2- and Wnt/EGFR/NF-kappaB-

signaling pathways inhibitor)

B)<smiles>[R]C(=O)Oc1cc2c(cc1[X])=c1c3c(n([R1])c1=2)C(=[NH2+])CC3</smiles>

iminio1, 2, 3, 4-tetrahydro cyclopent[b]indole carbamate
C)<smiles>[R]c1ccc2c(C)c([R])c(=O)oc2c1</smiles>

Coumarin derivatives
D)<smiles>[R]C1=CC(=O)c2cc(OCC(=C)/C=C\C)ccc2C1</smiles>
Chromone derivatives

(targets AChE and MAO)

E)<smiles>O=C(CCCCC1CCSS1)NCCNc1c2c(nc3cc(Cl)ccc13)CCCC2</smiles>

Liprocrine

(targets AChE and ROS)

F)<smiles>COc1ccccc1CN(C)CCCCCC(=O)N(C)CCCCCCCCN(C)C(=O)CCCCCN(C)Cc1ccccc1OC</smiles>

Caproctamine

(targets AChE and muscarinic M2 receptor) 
G)

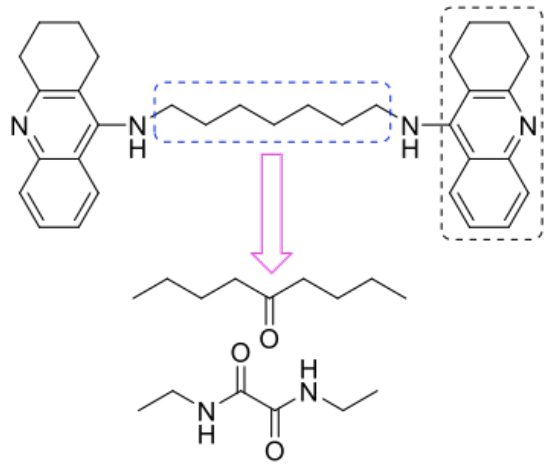

$\widehat{\mathrm{O}} \mathrm{N}$

Tacrine Derivative

(active against human $\mathrm{AChE}$, inhibit

AChE induced amyloid $\beta$.Aggregation)

H)

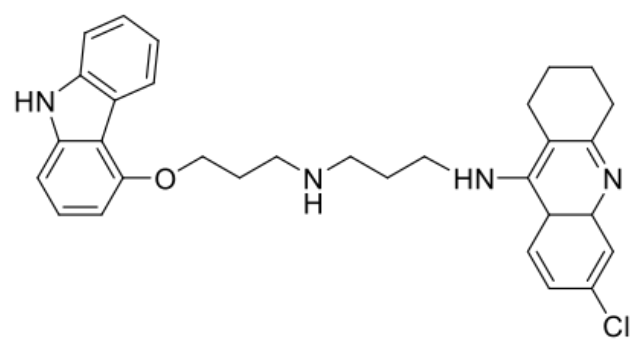

Carbacrine

(inhibits AChE, $\beta$ amyloid aggregation and NMDA receptors)

l)<smiles>CCN(CC)Cc1ccccc1OC</smiles>

\section{Memoquin}

(acetylcholinesterase and $\beta$-secretase-1 inhibitor)

J)<smiles>C#CCNC1CCc2ccc(OC(=O)N(C)CC)cc21</smiles>

Ladostigil
K)<smiles>C=CCN(C)Cc1ccc(O)c2ncccc12</smiles>

M30

(Multitarget Anti Parkinson and Anti Alzheimer Drugs) 
L)

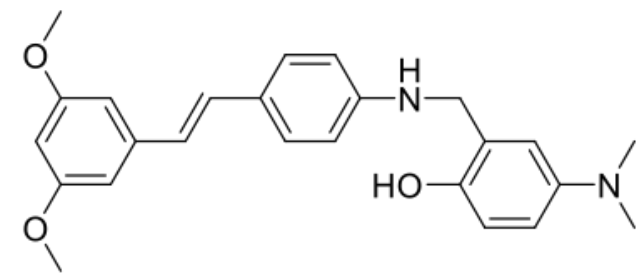

Resveratrol Derivatives

(inhibit A $\beta$-aggregation, AChE and antioxidant activity)

M)

PI3K inhibitor

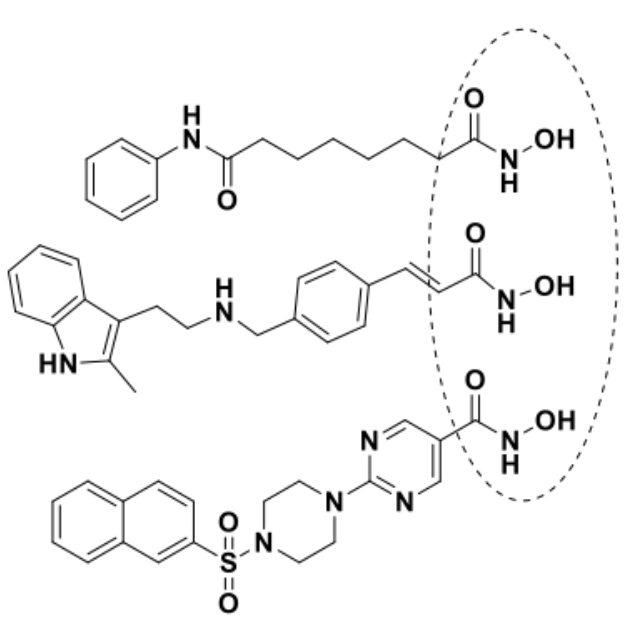

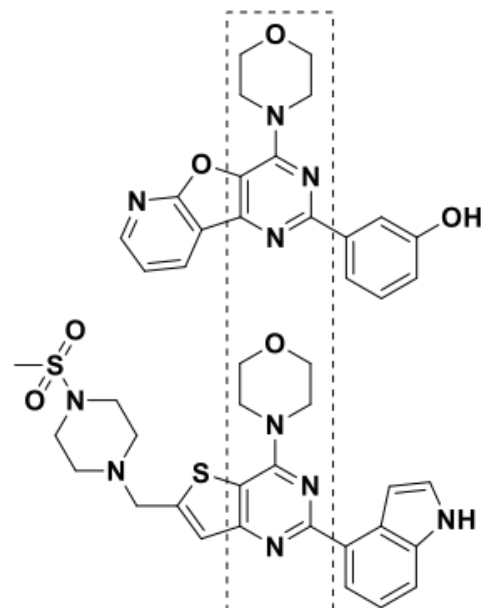<smiles>C=CC=C</smiles><smiles>CN(C)c1nc(N2CCOCC2)nc(-c2ccc(N)cc2C(F)(F)F)c1C1CCCCC1</smiles>

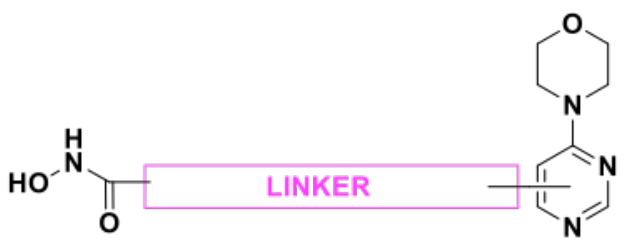

CUDC-907

(HDAC and PI3K inhibitor) 
Fig. 3. Chemical structure of (A) Multi-target neuroprotective compound Fisetin, Amyloid $\beta$-aggregation inhibiting multi-target compounds like (B) imino 1, 2, 3,4tetrahydrocyclopent[b]indole carbamates, (C) Coumarin derivatives, (D) Chromone derivates, (E) Lipocrine, (F) Caproctomine, (G) Bis-tacrine derivatives, (H) Carbacrine, (I) Memoquin, (J) Ladostigil, (K) M30 and (L) Resveratrol derivative. (M) A schematic representation of how the functional groups for inhibitory activity against both HDAC and PI3Ks (dotted box) are linked to design and generate CUDC907. 


\section{Figure 4}

A)

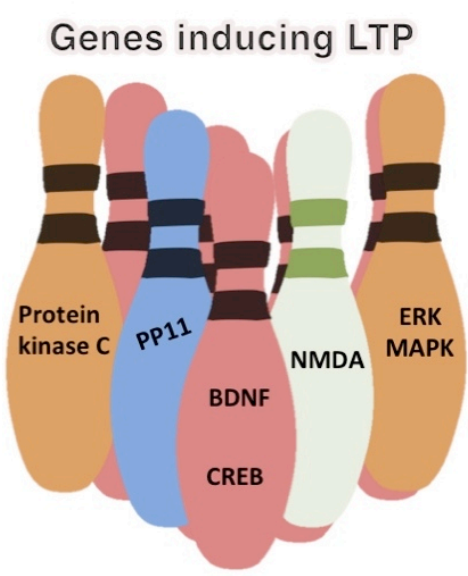

B) Target hit using induced LTP

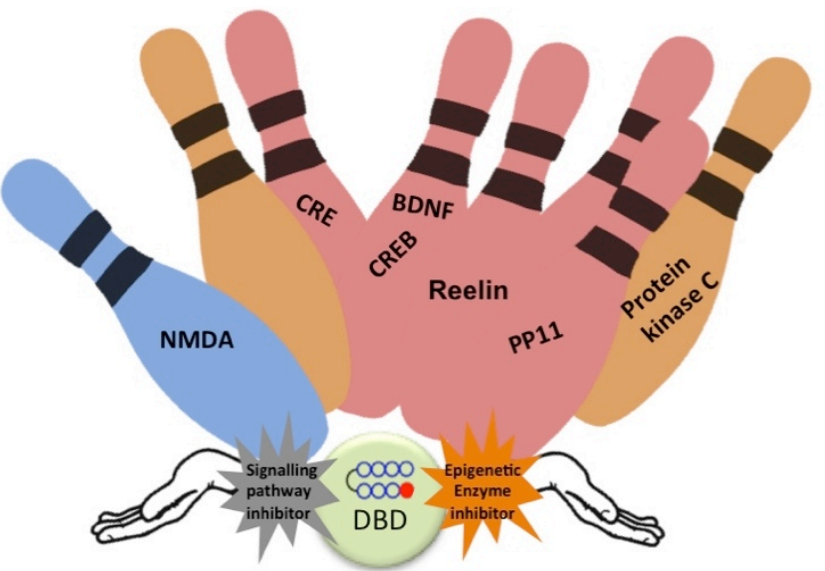

Next-generation multi-functional molecule

Fig. 4. (A) Some major factors responsible for LTP induction are shown. (B) Nextgeneration small molecules encompassing multi-functional properties (DNA binding domain (DBD) and modulators of factors conferring to signalling pathway and epigenetic enzymes) may effectively target the set of genes associated with LTP. The potential gene targets for LTP are represented as bowling balls and the compound with multifunctional properties is shown as a ball with waving hands. 


\begin{tabular}{|c|c|c|c|}
\hline $\begin{array}{l}\text { LTP-associated gene / } \\
\text { factor }\end{array}$ & Function & Model & Reference \\
\hline CREB & $\begin{array}{l}\text { Positive regulation of memory consolidation by modulating BDNF expression } \\
\text { by binding to CRE }\end{array}$ & Mice & 12 \\
\hline BDNF & $\begin{array}{l}\text { Positively modulates stable long-term potentiation (LTP) in hippocampus } \\
\text { through TrkB receptor }\end{array}$ & Mice & 48 \\
\hline Zif268 (EGR1) & Strengthening of memory trace by regulating proteins in the amygdala region & Mice & 49 \\
\hline Arc & Govern the key translation factors during LTP consolidation & Rat & 50 \\
\hline GAP43 & $\begin{array}{l}\text { LTP persistence through release of glutamate by PRKCA mediated } \\
\text { phosphorylation of GAP43 }\end{array}$ & Rat & 51 \\
\hline Reelin & Signal transduction through Apoer2 for the induction of LTP & Mice & 52 \\
\hline Synapsin I & $\begin{array}{l}\text { Contributes to LTP by increasing the release of neurotransmitter and number of } \\
\text { post synaptic neurons }\end{array}$ & Rat & 53 \\
\hline Neurotensin & Regulation of working memory & Homo sapiens & 54 \\
\hline DLG3 & $\begin{array}{l}\text { Interaction with NMDA receptor and plays an important role in LTP and } \\
\text { memory formation }\end{array}$ & Mice & 55 \\
\hline Integrin associated protein & Memory formation & Rat & 56 \\
\hline
\end{tabular}




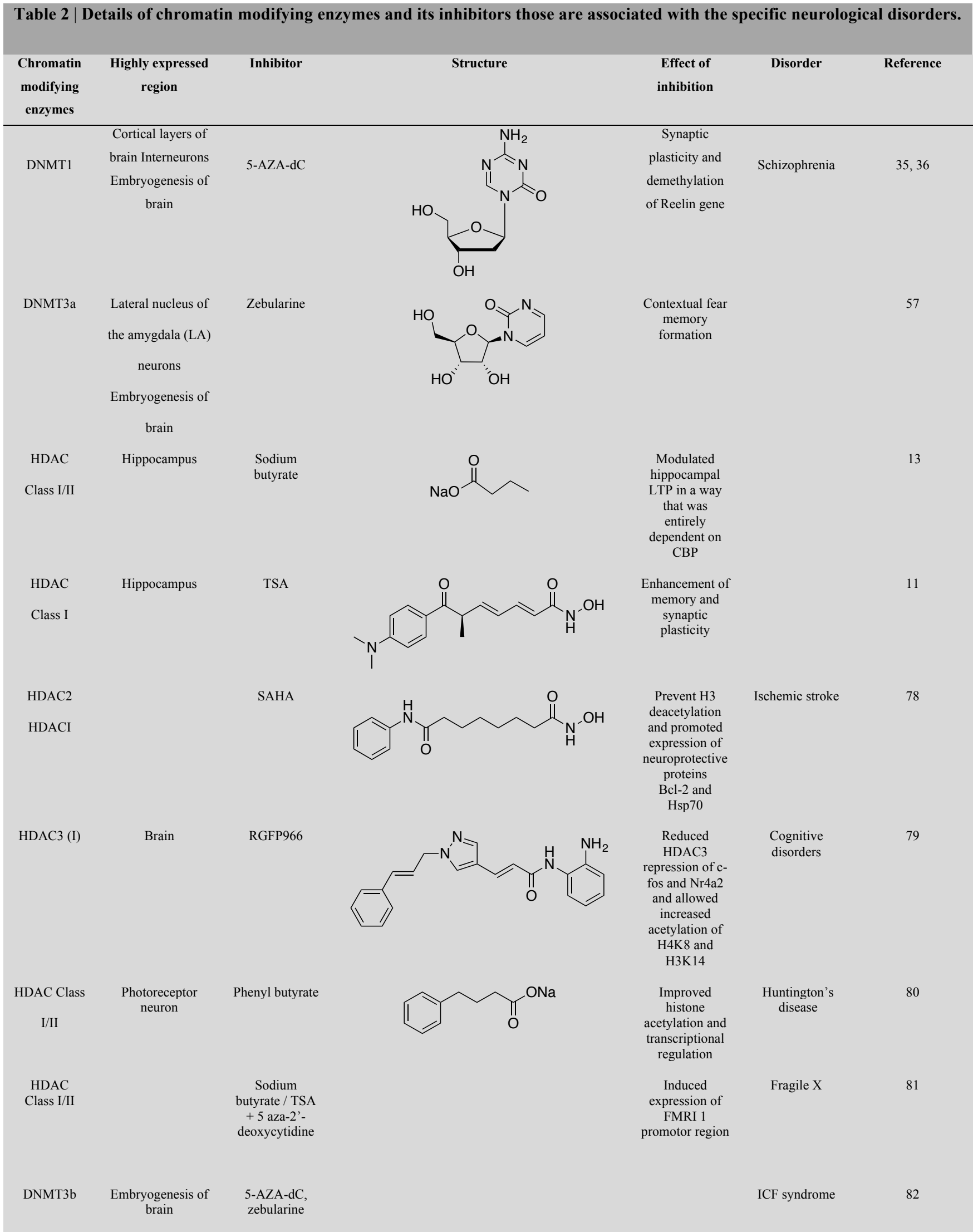

